\title{
Relato de uma Experiência de Intervenção na Perspectiva da Teoria Social Cognitiva de Carreira
}

\author{
Marilda Aparecida Dantas ${ }^{1, ~ *}$ \\ Orcid.org/0000-0001-6858-6421 \\ Roberta Gurgel Azzi ${ }^{1}$ \\ Orcid.org/0000-0003-0971-7852
}

${ }^{1}$ Universidade Estadual de Campinas, Campinas, SP, Brasil

\begin{abstract}
Resumo
O presente trabalho, de delineamento quase-experimental, investigou os efeitos de uma intervenção sobre exploração e planejamento quanto ao futuro acadêmico/carreira em estudantes do ensino médio público. A intervenção foi pautada na Teoria Social Cognitiva de Carreira e intermediada pelo livro $O$ Futuro está Logo Ali, Elpídio - Entre nesta Conversa sobre Pensar o que Vem Adiante. Foram verificadas as percepções de autoeficácia ocupacional de formação e interesses ocupacionais dos estudantes no pré e pós-teste. Participaram 166 estudantes do ensino médio de duas escolas públicas paulistas, divididos em grupo experimental e grupo controle. Foram utilizados um questionário de caracterização e a escala de autoeficácia ocupacional de formação e interesses ocupacionais. A intervenção ocorreu em encontros periódicos nas salas de aula da própria escola e com apoio de professores facilitadores. Os resultados das análises de correlações entre as crenças de autoeficácia ocupacional de formação e interesses ocupacionais indicaram convergências entre as categorizações de ocupações para ambos os grupos, sendo que o GE apresentou um maior número de correlações entre as variáveis no pós-teste. Identificaram-se contribuições da teoria para embasar perspectivas quanto aos projetos de vida no que tange ao planejamento de carreira de estudantes do ensino médio de escolas públicas.
\end{abstract}

Palavras-chave: Carreira, intervenção, ensino médio.

\section{Report on an Intervention Experiment from the Perspective of Social Cognitive Career Theory}

\begin{abstract}
This quasi-experimental designed work investigated the effects of an intervention focused on the exploration and planning of the professional/academic future of public high school students. This

* Endereço para correspondência: Rua Agostinho Rossi, 139, Parque Bela Vista, Pedreira, SP, Brasil 13920-000. E-mail: marildapsi@uol.com.br

A segunda autora agradece ao Apoio da Fundação de Amparo à Pesquisa do Estado de São Paulo (Fapesp), processo 2010/17954-9.
\end{abstract}


intervention was based on Social Cognitive Theory of Career and intermediated by the book O Futuro está Logo Ali, Elpídio - Entre nesta Conversa sobre Pensar o que Vem Adiante. The investigation happened through analyses of occupational self-efficacy of formation, and students occupational interests. There were a pre and a post-test. One hundred sixty-six students participated. They go to the second year of high school in two public schools in São Paulo State. The materials used were the instruments: (a) characterization questionnaire and (b) the Occupational Self-Efficacy of formation and occupational interests Scale. It was conducted in a collective way, through periodic meetings at the schools and with the teachers' support. The results of the correlations analyses (Spearman) between occupational selfefficacy of formation and occupational interests indicated similarities between the categorizations of occupations for both groups, having the experimental group presented more correlations. The results brought contributions to support life projects as to career planning of public high school students, guided by the Social Cognitive Theory of Career.

Keywords: Career, intervention, high school.

\section{Informe de una Experiencia de Intervención desde la Perspectiva de la Teoría Cognitiva Social de Carrera}

\section{Resumen}

Este trabajo, de diseño cuasi-experimental, investigó los efectos de una intervención sobre exploración y planificación del futuro académico/carrera de estudiantes de enseñanza secundaria pública. La intervención se basa en la Teoría Cognitiva Social de Carrera, intermediada por el libro $O$ Futuro está Logo Ali, Elpídio - Entre nesta Conversa sobre Pensar o que Vem Adiante. Se verificaron las percepciones de autoeficacia ocupacional de formación e intereses ocupacionales de estudiantes en el pre y post-test. Participaron 166 estudiantes de enseñanza secundaria de dos escuelas públicas de São Paulo, divididos en grupo experimental y grupo control. Se utilizaron un cuestionario de caracterización y una escala de autoeficacia ocupacional de formación e intereses ocupacionales. La intervención ocurrió en reuniones periódicas en aulas de la escuela con apoyo de maestros facilitadores. Los resultados del análisis de correlación entre creencias de autoeficacia ocupacional de formación e intereses ocupacionales indicaron convergencias entre las categorizaciones de ocupaciones de ambos grupos, y el grupo experimental presentó un número mayor de correlaciones entre las variables en el post-test. Se identificaron contribuciones de la teoría para apoyar las perspectivas de los proyectos de vida en relación con la planificación de la carrera de estudiantes de enseñanza secundaria de escuelas públicas.

Palabras clave: Carrera, intervención, enseñanza secundaria.

As práticas de orientação de carreira têm sido norteadas por diferentes teorias da ciência psicológica (Melo-Silva, Bonfim, Esbrogeo, \& Soares, 2003; Teixeira, 2007). Dentre elas, a que fundamenta o presente trabalho é a Teoria Social Cognitiva de Carreira (TSCC) que enfatiza o papel dos pensamentos autorreferentes na motivação e no comportamento humano, nos processos de desenvolvimento de interesses e nas escolhas do campo ocupacional e acadêmico (Lent, Brown, \& Hackett, 1994). Há no escopo da TSCC o construto das crenças de autoeficácia que referem-se as "crenças sobre as capacidades para organizar e executar o curso de uma determinada ação para produzir realizações" (Bandura, 1997, p. 3) que são consideradas como mecanismos centrais da agência humana. Segundo Bandura (2008) ser um agente significa fazer as coisas acontecerem de modo intencional, pelos próprios atos em que o sistema de crenças está incorporado. As crenças podem afetar a motivação, o bem-estar e as realizações, sendo que 
quando pouco se acredita que se pode conseguir efeitos desejáveis com suas ações, a tendência é de pouco incentivo para agir ou para perseverar diante das dificuldades (Bandura, 1997, 2008).

As crenças de autoeficácia são definidas por diferentes domínios e se caracterizam por atividades específicas requeridas para alcançar um determinado resultado num contexto particular, sendo que as áreas e os níveis em que as pessoas cultivam a sua percepção de autoeficácia diferem (Bandura, 1997, 2006; Polydoro, Vieira, Azzi, \& Dantas, 2012). Este aspecto é importante, pois indica que as pessoas podem ter diferentes percepções de autoeficácia em função de um domínio específico.

As crenças de autoeficácia pessoais podem ser, de alguma forma, alteradas por meio das fontes de informação de construção, fortalecimento ou enfraquecimento destas, podendo impactar no desempenho dos indivíduos. Bandura, $(1997,2008)$ aponta quatro fontes de informação de autoeficácia que colaboram para a percepção das crenças, a saber: (a) experiência direta com os resultados das ações que exercem um papel de indicador da capacidade; (b) a experiência vicária que modifica as crenças por meio da observação e comparação das competências e da realização de outros na consecução de objetivos; (c) a persuasão social que é o julgamento dos outros sobre as capacidades do indivíduo e (d) os estados físicos e afetivos onde o que e como as pessoas se sentem afetam as autopercepções quanto a suas capacidades. As construções e alterações das percepções podem ocorrer por meio da experiência de uma única ou mais fontes de informação em conjunto.

Além da autoeficácia, influenciam o funcionamento psicológico outros construtos como as expectativas de resultados e as intenções/objetivos. As expectativas de resultados são os julgamentos que as pessoas antecipam a provável consequência que os desempenhos podem produzir (Bandura, 1997), e os objetivos expressam a "determinação para engajar num curso específico de ação para atingir certos níveis de desempenho" (Bandura, 1986, p. 467). Nota-se que as percepções de eficácia não atuam de modo iso- lado e que as expectativas de resultados e os objetivos, como um conjunto de processos cognitivos estão envolvidos na construção da realização das pessoas.

Betz e Hackett (1981) iniciaram as pesquisas focando aspectos autorreferentes da TSC na carreira e desencadearam novos estudos que foram objetos de análises de Lent et al. (1994), dos quais formularam diferentes modelos teóricos sobre o desenvolvimento de carreira. $\mathrm{O}$ primeiro modelo é o de interesses, foco do presente estudo, e por ele é explicada a maneira como as pessoas desenvolvem seu gostar ou não das atividades acadêmicas e de carreira. As influências cognitivas e comportamentais vivenciadas mesmo quando os sujeitos não exercem uma atividade ocupacional, e sim diferentes atividades escolares, sociais ou domésticas podem servir de subsídios. O fato é que as pessoas estão expostas a uma diversidade de atividades que realizam ou não; ou seja, elas vivenciam situações de observação de outras pessoas em suas atividades (ocupacionais; Brown \& Lent, 2006). A inferência sobre a explicação desse modelo teórico de interesses é a de que tais experiências, embora sejam subjetivas e nem sempre planejadas de modo intencional, funcionariam como fontes de informação de autoeficácia.

Em uma perspectiva contextual como a teoria social cognitiva, as atividades experienciadas ou observadas pelas pessoas podem ser díspares em razão, por exemplo, da cultura em que as pessoas estão inseridas, do status socioeconômico, e ainda, pela distinção entre atividades exercidas tradicionalmente por homens ou mulheres. No modelo teórico entende-se que habitualmente as pessoas recebem incentivos para buscar atividades que consideram possíveis para si. O feedba$c k$ recebido de outras pessoas sobre as atividades realizadas, pode refinar suas habilidades, desenvolver padrões de desempenho, senso de eficácia em tarefas e fazer com que as pessoas adquiram certas expectativas sobre os resultados de seu desempenho inclusive para direções opostas (Brown \& Lent, 2006).

As pessoas tenderão a desenvolver interesses em atividades nas quais se sentem mais efica- 
zes (Coimbra \& Fontaine, 2010; Dantas \& Azzi, 2015; Lent, Brown, \& Larkin, 1986; Lent et al., 2001; Lent, Brown, Nota, \& Soresi, 2003; Lent, Paixão, Silva, \& Leitão, 2010; Lopez, Lent, Brow, \& Gore, 1997; Nunes \& Noronha, 2009, 2011). Os interesses, por sua vez, conduzem as pessoas a uma definição mais clara para as suas intenções/objetivos em atividades que aumentem a probabilidade subsequente de seleção de tarefas. $\mathrm{O}$ envolvimento em atividades ou práticas específicas conduz à produção de realizações que podem caracterizar sucessos ou fracassos, resultando na revisão da percepção das crenças de autoeficácia e das expectativas de resultados estimados para si. As pessoas estabelecem objetivos para o envolvimento em atividades guiadas por seus interesses e, em parte, pelas consequências que elas antecipam, contribuindo diretamente nas escolhas de atividades. A autoeficácia percebida e as expectativas de resultado exercem efeitos diretos sobre as metas de atividade e escolha, o que ocorre graças ao papel que têm de ajudar as pessoas a interpretar, organizar e aplicar suas habilidades (Brown \& Lent, 2006; Lent et al., 1994).

Apesar de tenderem a se manter estáveis, os interesses são passíveis de mudança, pois as percepções de crenças de autoeficácia e de expectativas de resultados são alteradas, não são fixas. A mudança pode ser explicada pela exposição a novas aprendizagens ou novas observações, tais como: avanços tecnológicos, capacitação ou reestruturação para o trabalho, as quais impactam ao retroalimentar as crenças de eficácia (Brown \& Lent, 2006).

Pesquisas com estudantes têm apontado que aqueles que se percebiam mais autoeficazes também percebiam maior amplitude nas opções de carreira (Lent, Brown, \& Larkin, 1984, 1986, 1987). Intervenções para o desenvolvimento de carreira pautadas pela TSCC com estudantes tem sido realizadas em diferentes países tais como Estados Unidos da América (Betz \& Shifano, 2000), Espanha (Martín \& Tejedor, 2004) e China (Wang, Zhang, \& Chao, 2010). De modo geral, os resultados das intervenções tem apontado para o fortalecimento das percepções de autoeficácia em diferentes domínios.
O que se nota é que no âmbito escolar, ainda que de modo indireto, são previstas intervenções sobre o desenvolvimento de carreira com estudantes. De acordo com os Parâmetros Curriculares Nacionais (Ministério da Educação, 2000), o papel da escola, além de contribuir para subsídios no desempenho escolar, deve observar a integração dos estudantes no mundo contemporâneo, tanto quanto às questões da cidadania como as do trabalho. Quanto a percepção dos estudantes sobre a contribuição da escola no processo de escolha de uma profissão, parece que nem sempre o é reconhecida ou e pouco reconhecida, ou ainda o auxílio pode ocorrer de forma relativa e indireta, apenas pelo fato de estarem frequentando a escola, apontou o estudo de Valore e Cavallet (2012). Outros trabalhos apontam intervenções no espaço escolar como proposta de transversalidade e integralidade do trabalho na educação básica (Aguiar \& Conceição, 2011; Aita, Ricci, \& Tuleski, 2012; Lamas, Pereira, \& Barbosa, 2008). Não faltam argumentos para considerar a contribuição da escola, como grupo social no qual o jovem está inserido, para a construção de projetos de vida e fornecer elementos de base para sua escolha, como abordou Kober (2008).

As expectativas em torno do contexto escolar como um espaço de contribuições para reflexões sobre a carreira e a perspectiva teórica da TSCC inspiraram a intervenção desenvolvida do presente estudo, cujo objetivo foi de verificar as relações entre crenças de autoeficácia ocupacional de formação e interesses ocupacionais em estudantes de nível médio no pré e pós-teste.

\section{Método}

A proposta da presente pesquisa caracteriza-se pelo delineamento quase-experimental e longitudinal (Campos, 2004), cuja intervenção foi mediada pelo livro "O Futuro está Logo Ali, Elpídio" (Azzi, Dantas, Benassi, \& Guerreiro-Casanova, 2013).

\section{Participantes}

Participaram 166 estudantes de nível médio oriundos de duas escolas públicas do estado de São Paulo (escola 1 e 2). Os 166 estudantes fo- 
ram organizados em grupo experimental (GE), participantes da intervenção; e grupo controle (GC), composto por apenas os que responderam aos instrumentos de investigação no pré-teste e no pós-teste. O critério utilizado de organização dos grupos foi em função da disponibilidade de horário do professor facilitador na respectiva turma. A seguir são apresentados os dados de caracterização pessoal dos participantes.

Grupo Experimental (GE). O GE foi composto por 103 estudantes sendo $62(60,19 \%)$ da escola 1 e por $41(39,81 \%)$ da escola 2 , dos quais $64(62,14 \%)$ eram do sexo feminino e 39 $(37,86 \%)$ do masculino, a média de idade foi de 15,7 anos; 56 (54,90\%) eram do turno manhã e $46(45,10 \%)$ da noite, um deles não respondeu. A escola 1 foi composta pela turma B com 32 estudantes $(31,07 \%)$ e pela turma $\mathrm{E}$ com 30 estudantes $(29,13 \%)$. A escola 2 compôs-se pela turma A, com 24 estudantes $(23,30 \%)$, e pela turma $\mathrm{C}$, com 17 (16,50\%). Todos residiam na área urbana e as etnias de acordo com o que declararam, se dividiram em: $53(51,46 \%)$ brancos, 37 (35,92\%) pardos, 7 (6,80\%) negros, 3 (2,91\%) amarelo e $3(2,91 \%)$ indígena.

Grupo Controle (GC). O GC foi composto por 63 estudantes sendo $58(92,06 \%)$ da escola 1 e $5(7,94 \%)$ da escola 2 , totalizando, dentre os quais $40(63,49 \%)$ eram do sexo feminino e 23 $(36,51 \%)$ do masculino, com idade média de idade de 15,5 anos; 35 (55,56\%) eram do turno da manhã e $28(44,44 \%)$ da noite. As turmas C com 28 estudantes $(44,44 \%)$ e D com $30(47,62 \%)$ eram provenientes da escola 1 , e a turma $\mathrm{B}$ com $5(7,94 \%)$ era oriunda da escola 2 . Apenas 5 $(8,06 \%)$ deles residiam em área rural. Os participantes do GC se declararam: 49 (77,78\%) brancos, $9(14,29 \%)$ pardos e $5(7,94 \%)$ negros.

\section{Instrumentos}

Para a realização da intervenção foi utilizado: Livro O Futuro está Logo Ali, Elpídio Entre nesta Conversa sobre Pensar o que Vem Adiante (Azzi et al., 2013), da série "Conversas do Elpídio", coleção direcionada aos estudantes do ensino médio. Elpídio, um jovem estudante, é o personagem que dialoga com o leitor a respeito de sua trajetória no ensino médio, suas reflexões sobre o seu futuro quanto as escolhas acadêmicas e de carreira nos 14 capítulos que o estruturam. Um maior detalhamento do material utilizado pode ser observado em Dantas (2015). O objetivo é de promover reflexões sobre a vida acadêmica e de carreira por meio de atividades de discussões, questões, pesquisas de informações em sites e entrevistas.

Para a coleta de dados foram utilizados: (a) Questionário de caracterização (Guerreiro-Casanova, Azzi, \& Dantas, 2010); e (b) Escala de Autoeficácia Ocupacional de Formação e Interesses (Coimbra, 2000) que foi adaptada para o contexto brasileiro, a partir da versão portuguesa, na qual demonstrou evidências de validade (Dantas, Azzi, \& Noronha, s.d.). A versão adaptada foi composta por 2 subescalas com 51 itens (ocupações) cada uma. A primeira subescala corresponde à autoeficácia do respondente no que se refere à capacidade em completar com sucesso a formação necessária para cada ocupação. O respondente deve assinalar uma das duas opções de respostas: "sim" ou "não" para cada ocupação. Caso assinale "sim", é preciso apontar numa escala Likert ( 1 "nenhuma certeza" até 10 "toda a certeza") sobre sua percepção da capacidade. A segunda subescala refere-se ao interesse do respondente para cada uma das ocupações com 3 possibilidades de respostas ("não gosto", "indiferente" ou "gosto").

\section{Procedimentos de Coleta de Dados}

A participação foi voluntária e para os menores de 18 anos os pais/responsáveis assinaram o Termo de Consentimento Livre e Esclarecido ${ }^{1}$. Contatou-se a direção das instituições escolares para apresentação dos objetivos do projeto de pesquisa, bem como a preparação para a intervenção e a coleta de dados. O projeto foi apresentado aos professores numa reunião de HTPC na qual foram convidados a aplicação da intervenção nas segundas séries do ensino médio. A

\footnotetext{
O projeto de pesquisa foi submetido ao Comitê de Ética em Pesquisa da Faculdade de Ciências Médicas da Universidade Estadual de Campinas (Unicamp) e foi aprovado conforme documento CAAE 09248912.0.00005404.
} 
coleta de dados foi coletiva e em sala de aula, o preenchimento dos questionários foi realizada como pré e pós-teste, não houve tempo limite para responder, sendo de 50 minutos o tempo médio de preenchimento. Cada participante do GE recebeu um livro (Azzi et al., 2013) ${ }^{2}$, com o qual acompanharam em sala de aula as atividades conduzidas pelos professores facilitadores conforme a descrição a seguir.

\section{Procedimentos da Intervenção Realizada}

O objetivo da intervenção com os estudantes GE foi de promover reflexões quanto à exploração e planejamento acadêmico/carreira. $\mathrm{O}$ processo de intervenção ocorreu durante 4 meses (entre abril a agosto de 2013) com a média de 12 encontros realizados em sala de aula, sendo um por semana, em dias diferentes conforme o horário de aula do professor na turma. Os professores facilitadores receberam o livro e um caderno para anotações e uma nova reunião foi realizada com eles tendo como propósito trocar impressões e esclarecimentos sobre a estrutura do livro. Os professores facilitadores aplicaram as seguintes metodologias: (a) A intervenção iniciou-se após a realização do pré-teste aplicado pela pesquisadora em dia e horário acordados, bem como o pós-teste ao final da intervenção. (b) Acordo pedagógico com os estudantes sobre a realização da intervenção e a conciliação com o conteúdo da respectiva disciplina, pois não houve acréscimo de carga horária. (c) Os professores facilitadores utilizaram estratégias com autonomia, destacando-se a leitura individual, leitura compartilhada, debates, registros de reflexões e tarefas. (d) Não houve atribuição de nota avaliativa ao estudante da respectiva disciplina, nem outros benefícios ou prejuízos aos professores ou aos alunos.

A proposta do livro prevê seu uso de modo autônomo pelo estudante ou conduzido em grupo por um facilitador, por isso não houve uma capacitação específica para os professores.

2 A editora Casa do Psicólogo editou e cedeu os livros para a realização da pesquisa.

\section{Procedimentos de Análises de Dados}

Os dados coletados foram analisados por meio do programa estatístico SAS (Statistical Analysis System, versão 9.2). Foram selecionados aleatoriamente $20 \%$ das respostas dos participantes para efeito de conferência não sendo encontradas discrepâncias nessa verificação.

Os itens da Escala de Autoeficácia Ocupacional de Formação e Interesses foram agrupados em função das características das ocupações e associadas à Classificação Nacional das Atividades Econômicas (CNAE), cuja organização é gerenciada pelo Instituto Brasileiro de Geografia e Estatística (IBGE). A CNAE é uma ferramenta padronizada para uso na pesquisa de informações por tipo de atividade econômica em nível nacional e internacional. A versão utilizada foi a 2.0, de 2007, uma classificação da Classificación Industrial Internacional Uniforme (CIIU) adotada pelas Nações Unidas e utilizada como referência em dados estatísticos econômicos e socioeconômicos. Para a organização dos itens relacionados ao presente trabalho, elegeu-se o primeiro nível hierárquico de classificação por seções representando diferentes áreas de atividades econômicas (IBGE, 2007).

Para a realização deste procedimento houve a colaboração de 3 juízes com conhecimento e experiência na área do mundo do trabalho e de orientação profissional. A análise dos juízes consistiu em alocar cada ocupação de acordo com suas características, para uma ou mais CNAE, além disso utilizou-se um quarto critério, o de localização e classificação segundo a Comissão Nacional de Classificação (Concla), mediante a localização da ocupação no site <www.concla. ibge.gov.br $>$ e seu possível enquadramento na CNAE.

Houve concordância total entre os juízes para 27 ocupações das 51, sendo indicada a ocupação para a mesma atividade econômica. Houve concordância parcial entre os juízes, na qual indicaram duas áreas de atividade econômica, para 20 ocupações dos 51 itens. E, houve outras 4 ocupações também com concordância parcial entre os juízes, em que foram indicadas três ou mais atividades econômicas. Embora não tenha sido identificada a concordância total para todas 
as ocupações, é possível considerar as alocações delas em diferentes áreas, isso devido ao fato de que uma mesma ocupação pode atuar em diferentes segmentos econômicos.

Os resultados encontrados a partir do agrupamento para cada Seção (IBGE, 2007) indicaram que vários grupos apresentaram coeficientes de alfa inexpressivos (abaixo de 0,60). Diante dessa condição os agrupamentos foram revistos. Dessa forma, uniram-se grupos de atividades econômicas similares (Seção) - e consequentemente os seus itens (ocupações) - em novos agrupamentos. A Tabela 1 apresenta os agrupamentos finais.

\section{Tabela 1}

Agrupamento das Seções da CNAE versão 2.0 (Classificação Nacional das Atividades Econômicas) - Versão Final

Seção - Denominação

Ocupações

A Agricultura, pecuária, produção florestal, pesca e aquicultura

(Agricultor, Pescador, Agrônomo, Biólogo, Veterinário, Engenheiro)

B Indústrias extrativas (Operário de Fábrica, Engenheiro)

C Indústrias de transformação (Operário de Fábrica, Engenheiro)

D Eletricidade e gás (Eletricista, Engenheiro)

E Água, esgoto, atividades de gestão de resíduos e descontaminação (Engenheiro)

F Construção (Op. Construção, Arquiteto, Engenheiro)

G Comércio; reparação de veículos automotores e motocicletas

(Comerciante, Emp. Comércio - balconista, caixa, Mecânico)

H Transporte, armazenagem e correio (Motorista prof., Engenheiro)

I Alojamento e alimentação (Cozinheiro/ Padeiro/ Pasteleiro, Técnico em Turismo)

J Informação e comunicação (Jornalista, Técnico em Informática, Escritor)

$\mathrm{K}$ Atividades financeiras, de seguros e serviços relacionados (Contabilista)

M Atividades profissionais, científicas e técnicas (Biólogo, Advogado, Engenheiro, Juiz, Veterinário, Comerciante, Psicólogo, Sociólogo, Técnico em Informática, Técnico em Turismo, Músico, Diretor ou Gerente, Agrônomo, Eletricista, Escritor, Estilista de moda, Médico, Crítico literário)

N Atividades administrativas e serviços complementares (Assist. Adm., Diretor ou Gerente, Recepcionista/Telef./ Porteiro, Secretário)

O Administração pública, defesa e seguridade social (Político, Diplomata, Bombeiro, Policial, Advogado, Juiz)

U Organismos internacionais e outras instituições extraterritoriais (Diplomata)

P Educação (Prof. Ed. Fund., Prof. Ed. Inf., Prof. E.M., Monitor de Crianças)

Q Saúde humana e serviços sociais (Assistente Social, Fisioterapeuta, Psicólogo, Sociólogo, Agente de Saúde, Médico, Enfermeiro, Bombeiro, Esteticista, Biólogo)

R Artes, cultura, esporte e recreação (Atleta ou Jogador prof., Ator/Atriz, Técnico em Turismo, Músico/Musicista, Estilista de Moda, Monitor de Crianças, Escritor, Crítico literário, Fotógrafo)

S Outras atividades de serviços (Cabeleireiro, Barbeiro, Esteticista, Fotógrafo, Recepcionista/Telef./ Porteiro)

T Serviços domésticos (Empregada Doméstica) 
Os coeficientes de alfa identificados no agrupamento final foram considerados adequados variando entre 0,62 a 0,86 . Finalizados os procedimentos de organização dos itens foi possível realizar as análises considerando as ocupações conforme a CNAE.

\section{Resultados}

Os dados foram submetidos ao teste de normalidade Shapiro-Wilk ( $\rho<5 \%$ ), o que caracterizou uma distribuição não normal, indicando a utilização do teste de correlação de Spearman. As correlações entre as percepções de autoeficácia ocupacional de formação e interesses (Lent et al., 1994) foram realizadas em cada grupo (GE e GC) e no pré e no pós-teste. São apresentados os resultados do GC no pré e no pós-teste e em seguida os do pré e do pós-teste do GE. Nas tabelas de cada grupo foram destacadas em negrito as correlações com valor de $\rho=<0,0001$. O termo 'correspondente' foi utilizado para designar as ocupações das mesmas seções da CNAE quando comparadas entre as crenças de autoeficácia e interesses, e 'não correspondentes' para as ocupações de diferentes seções.

Nas seções da CNAE das crenças de autoeficácia ocupacional de formação e os interesses ocupacionais no pré-teste do GC, observou-se correlações positivas e significativas para todas as seções correspondentes. É possível compreender que os estudantes que se percebiam autoeficazes para concluir com sucesso a formação necessária em ocupações da CNAE A (agricultu-

Tabela 2

Correlações de Spearman entre Autoeficácia Ocupacional (formação) e Interesses Ocupacionais pela CNAE - GC (pré-teste) - $(N=63)$

\begin{tabular}{|c|c|c|c|c|c|c|c|c|c|c|c|}
\hline & $\begin{array}{l}\text { Inter } \\
\mathrm{A}^{* *}\end{array}$ & $\begin{array}{c}\text { Inter } \\
\text { BCDEF }\end{array}$ & $\begin{array}{l}\text { Inter } \\
\text { GHI }\end{array}$ & $\begin{array}{c}\text { Inter } \\
\mathrm{JK}\end{array}$ & $\begin{array}{c}\text { Inter } \\
\mathrm{M}\end{array}$ & $\begin{array}{c}\text { Inter } \\
\mathrm{N}\end{array}$ & $\begin{array}{c}\text { Inter } \\
\text { OU }\end{array}$ & $\begin{array}{c}\text { Inter } \\
\mathrm{P}\end{array}$ & $\begin{array}{c}\text { Inter } \\
\mathrm{Q}\end{array}$ & $\begin{array}{c}\text { Inter } \\
\mathrm{R}\end{array}$ & $\begin{array}{c}\text { Inter } \\
\text { ST }\end{array}$ \\
\hline FormA* & $\begin{array}{c}r=0,74 \\
p<0,0001\end{array}$ & $\begin{array}{c}0,40 \\
0,0011\end{array}$ & $\begin{array}{c}0,46 \\
0,0001\end{array}$ & $\begin{array}{c}0,29 \\
0,017\end{array}$ & $\begin{array}{c}0,60 \\
<0,0001\end{array}$ & $\begin{array}{c}0,27 \\
0,028\end{array}$ & $\begin{array}{c}0,24 \\
0,052\end{array}$ & $\begin{array}{c}0,18 \\
0,157\end{array}$ & $\begin{array}{c}0,54 \\
<0,0001\end{array}$ & $\begin{array}{c}0,23 \\
0,068\end{array}$ & $\begin{array}{c}0,08 \\
0,501\end{array}$ \\
\hline $\begin{array}{l}\text { Form } \\
\text { BCDEF }\end{array}$ & $\begin{array}{c}0,36 \\
0,003\end{array}$ & $\begin{array}{c}0,68 \\
<0,0001\end{array}$ & $\begin{array}{c}0,46 \\
0,0001\end{array}$ & & $\begin{array}{c}0,25 \\
0,043\end{array}$ & & $\begin{array}{c}0,03 \\
0,784\end{array}$ & & $\begin{array}{c}0,11 \\
0,385\end{array}$ & & $\begin{array}{l}-0,23 \\
0,059\end{array}$ \\
\hline HI & & & $\begin{array}{c}0,61 \\
<0,0001\end{array}$ & & & & & 0,047 & 0,001 & & $\begin{array}{c}0,17 \\
0,161\end{array}$ \\
\hline FormJK & $\begin{array}{c}0,13 \\
0,277\end{array}$ & $\begin{array}{c}0,30 \\
0,015\end{array}$ & $\begin{array}{c}0,29 \\
0,019\end{array}$ & $\begin{array}{c}0,68 \\
<0,0001\end{array}$ & $\begin{array}{c}0,38 \\
0,002\end{array}$ & $\begin{array}{r}0, \\
0,0\end{array}$ & $\begin{array}{c}0,28 \\
0,021\end{array}$ & $\begin{array}{c}0,01 \\
0,902\end{array}$ & $\begin{array}{c}0,29 \\
0,017\end{array}$ & & $\begin{array}{c}0,05 \\
0,678\end{array}$ \\
\hline FormM & $\begin{array}{c}0,47 \\
<0,0001\end{array}$ & $\begin{array}{c}0,24 \\
0,048\end{array}$ & $\begin{array}{c}0,40 \\
0,001\end{array}$ & $\begin{array}{c}0,42 \\
0,001\end{array}$ & $\begin{array}{c}0,63 \\
<0,0001\end{array}$ & $\begin{array}{c}0,35 \\
0,0042\end{array}$ & $\begin{array}{c}0,44 \\
0,001\end{array}$ & & $\begin{array}{c}0,61 \\
<0,0001\end{array}$ & $\begin{array}{c}0,41 \\
0,0008\end{array}$ & $\begin{array}{c}0,25 \\
0,041\end{array}$ \\
\hline FormN & $\begin{array}{c}0,14 \\
0,271\end{array}$ & $\begin{array}{c}0,04 \\
0,722\end{array}$ & $\begin{array}{c}0,33 \\
0,007\end{array}$ & $\begin{array}{c}0,41 \\
0,0006\end{array}$ & $\begin{array}{c}0,32 \\
0,010\end{array}$ & $\begin{array}{r}0, \\
<0,\end{array}$ & $\begin{array}{c}0,04 \\
0,716\end{array}$ & $\begin{array}{c}0,38 \\
0,001\end{array}$ & $\begin{array}{c}0,33 \\
0,007\end{array}$ & & $\begin{array}{c}0,45 \\
0,0002\end{array}$ \\
\hline FormOU & $\begin{array}{c}0,22 \\
0,074\end{array}$ & $\begin{array}{c}0,23 \\
0,066\end{array}$ & $\begin{array}{c}0,24 \\
0,057\end{array}$ & $\begin{array}{c}0,41 \\
0,0007\end{array}$ & $\begin{array}{c}0,44 \\
0,0002\end{array}$ & $\begin{array}{c}0,24 \\
0,049\end{array}$ & $\begin{array}{c}0,63 \\
<0,0001\end{array}$ & $\begin{array}{c}0,11 \\
0,369\end{array}$ & $\begin{array}{c}0,38 \\
0,001\end{array}$ & $\begin{array}{c}0,29 \\
0,019\end{array}$ & $\begin{array}{c}0,12 \\
0,318\end{array}$ \\
\hline FormP & $\begin{array}{c}0,14 \\
0,252\end{array}$ & $\begin{array}{l}-0,01 \\
0,884\end{array}$ & $\begin{array}{c}0,18 \\
0,141\end{array}$ & $\begin{array}{c}0,19 \\
0,120\end{array}$ & $\begin{array}{c}0,18 \\
0,146\end{array}$ & $\begin{array}{c}0,42 \\
0,0005\end{array}$ & $\begin{array}{c}0,04 \\
0,708\end{array}$ & $\begin{array}{c}0,67 \\
<0,0001\end{array}$ & $\begin{array}{c}0,25 \\
0,041\end{array}$ & $\begin{array}{c}0,35 \\
0,004\end{array}$ & $\begin{array}{c}0,43 \\
0,0003\end{array}$ \\
\hline FormQ & $\begin{array}{c}0,47 \\
<0,0001\end{array}$ & $\begin{array}{c}0,09 \\
0,481\end{array}$ & $\begin{array}{c}0,32 \\
0,009\end{array}$ & $\begin{array}{c}0,33 \\
0,008\end{array}$ & $\begin{array}{c}0,58 \\
<0,0001\end{array}$ & $\begin{array}{c}0,34 \\
0,0063\end{array}$ & $\begin{array}{c}0,31 \\
0,013\end{array}$ & $\begin{array}{c}0,33 \\
0,007\end{array}$ & $\begin{array}{c}0,74 \\
<0,0001\end{array}$ & $\begin{array}{c}0,40 \\
0,001\end{array}$ & $\begin{array}{c}0,42 \\
0,0005\end{array}$ \\
\hline FormR & $\begin{array}{c}0,18 \\
0,150\end{array}$ & $\begin{array}{l}-0,06 \\
0,625\end{array}$ & $\begin{array}{c}0,13 \\
0,302\end{array}$ & $\begin{array}{c}0,33 \\
0,007\end{array}$ & $\begin{array}{c}0,30 \\
0,015\end{array}$ & $\begin{array}{c}0,33 \\
0,333\end{array}$ & $\begin{array}{c}0,22 \\
0,070\end{array}$ & $\begin{array}{c}0,35 \\
0,004\end{array}$ & $\begin{array}{c}0,33 \\
0,007\end{array}$ & $\begin{array}{c}0,47 \\
0,001\end{array}$ & $\begin{array}{c}0,32 \\
0,010\end{array}$ \\
\hline FormST & $\begin{array}{c}0,05 \\
0,682\end{array}$ & $\begin{array}{l}-0,22 \\
0,071\end{array}$ & $\begin{array}{c}0,12 \\
0,335\end{array}$ & $\begin{array}{c}0,19 \\
0,125\end{array}$ & $\begin{array}{c}0,12 \\
0,341\end{array}$ & $\begin{array}{c}0,48 \\
<0,0001\end{array}$ & $\begin{array}{c}0,05 \\
0,680\end{array}$ & $\begin{array}{c}0,46 \\
0,001\end{array}$ & $\begin{array}{c}0,25 \\
0,040\end{array}$ & $\begin{array}{c}0,33 \\
0,006\end{array}$ & $\begin{array}{c}0,62 \\
<0,0001\end{array}$ \\
\hline
\end{tabular}

*Autoeficácia ocupacional para formação de categoria CNAE na atividade A. **Interesses Ocupacionais de categoria CNAE na atividade $\mathrm{A}$. 
ra, pecuária, produção florestal, pesca e aquicultura), por exemplo, também se interessavam pelas respectivas ocupações. As correlações foram de intensidades moderadas a fortes, variando entre 0,61 a 0,74 (Dancey \& Reidy, 2006). Correlações positivas e significativas entre seções da CNAE não correspondentes também foram identificadas em oito ocorrências, das quais a intensidade dos coeficientes foi moderada, variando entre 0,47 a 0,62 como observados na Tabela 2 .

A partir dos resultados no pós-teste do GC identificou-se que as correlações positivas entre autoeficácia ocupacional de formação e os interesses ocupacionais se mantiveram para as seções correspondentes da CNAE. Todas as correlações foram de intensidades moderadas, variando entre 0,50 a 0,65 . Foram identificadas apenas duas ocorrências de correlações positivas e significativas moderadas para seções não correspondentes, ocorrendo entre interesses CNAE JK (Jornalista, Técnico em Informática, Escritor/Contabilista) e autoeficácia CNAE Q (Assistente Social, Fisioterapeuta, Psicólogo, Sociólogo, Agente de Saúde, Médico, Enfermeiro, Bombeiro, Esteticista, Biólogo; 0,62), e entre interesses CNAE ST (Cabeleireiro, Barbeiro, Esteticista, Fotógrafo, Recepcionista/Telef./ Porteiro e Empregada Doméstica) e autoeficácia CNAE N (Assist. Adm., Diretor ou Gerente, Recepcionista/Telef./ Porteiro, Secretário; 0,48), como se apresenta na Tabela 3. Notou-se uma sutil diminuição para todos os valores dos coeficientes de correlação das seções correspondentes entre o pré e o pós-teste do GC.

Tabela 3

Correlações de Spearman entre Autoeficácia Ocupacional de Formação e Interesses Ocupacionais pela CNAE - GC (pós-teste $)-(N=63)$

\begin{tabular}{|c|c|c|c|c|c|c|c|c|c|c|c|}
\hline & $\begin{array}{l}\text { Inter } \\
A^{* *}\end{array}$ & $\begin{array}{c}\text { Inter } \\
\text { BCDEF }\end{array}$ & $\begin{array}{l}\text { Inter } \\
\text { GHI }\end{array}$ & $\begin{array}{l}\text { Inter } \\
\text { JK }\end{array}$ & $\begin{array}{c}\text { Inter } \\
\mathrm{M}\end{array}$ & $\begin{array}{c}\text { Inter } \\
\mathrm{N}\end{array}$ & $\begin{array}{c}\text { Inter } \\
\mathrm{OU}\end{array}$ & $\begin{array}{c}\text { Inter } \\
\mathrm{P}\end{array}$ & $\begin{array}{c}\text { Inter } \\
\mathrm{Q}\end{array}$ & $\begin{array}{c}\text { Inter } \\
\mathrm{R}\end{array}$ & $\begin{array}{l}\text { Inter } \\
\text { ST }\end{array}$ \\
\hline & 0,56 & & & & & & & & & & 0,27 \\
\hline$A^{*}$ & $=0,0001$ & 0,0011 & 0,0731 & 0,1871 & 0,0030 & 0,0153 & 0,0082 & 0,0054 & 0,0010 &, 2914 & 0,0322 \\
\hline & & 0,60 & & & 023 & 016 & & & & & 0 \\
\hline & 0,0063 & $<\mathbf{0 , 0 0 0 1}$ & 0,0251 & 0,0595 & 0,0661 & & & & 0,5502 & & 0,9809 \\
\hline HI & $\begin{array}{c}0,27 \\
0,0332\end{array}$ & $\begin{array}{c}0,39 \\
0,0016\end{array}$ & $\begin{array}{c}0,57 \\
<\mathbf{0 , 0 0 0 1}\end{array}$ & $\begin{array}{c}0,32 \\
0,0103\end{array}$ & $\begin{array}{c}0,36 \\
0,0034\end{array}$ & $\begin{array}{c}0,41 \\
0,0006\end{array}$ & $\begin{array}{c}0,20 \\
0,1033\end{array}$ & $\begin{array}{c}0,18 \\
0,1476\end{array}$ & $\begin{array}{c}0,31 \\
0,0111\end{array}$ & $\begin{array}{c}0,20 \\
0,1066\end{array}$ & $\begin{array}{c}0,31 \\
0,0120\end{array}$ \\
\hline For & $\begin{array}{c}0,07 \\
0,5562\end{array}$ & $\begin{array}{c}0,14 \\
0,2691\end{array}$ & 0,52 & $\begin{array}{c}0,59 \\
<\mathbf{0 , 0 0 0 1}\end{array}$ & $\begin{array}{c}0,27 \\
0,0303\end{array}$ & $\begin{array}{c}0,11 \\
0,3619\end{array}$ & $\begin{array}{c}0,22 \\
0,0769\end{array}$ & $\begin{array}{c}0,15 \\
0,2306\end{array}$ & $\begin{array}{c}0,19 \\
0,1189\end{array}$ & $\begin{array}{c}0,17 \\
0,1736\end{array}$ & $\begin{array}{c}0,12 \\
0,3466\end{array}$ \\
\hline M & $\begin{array}{r}0,3 \\
0,00\end{array}$ & $\begin{array}{c}0,26 \\
0,0363\end{array}$ & $\begin{array}{c}0,25 \\
0,0459\end{array}$ & $\begin{array}{c}0,44 \\
0,0003\end{array}$ & $\begin{array}{c}0,51 \\
<0,0001\end{array}$ & $\begin{array}{c}0,30 \\
0,0168\end{array}$ & $\begin{array}{c}0,37 \\
0,0027\end{array}$ & $\begin{array}{c}0,15 \\
0,2127\end{array}$ & $\begin{array}{c}0,45 \\
0,0002\end{array}$ & $\begin{array}{c}0,28 \\
0,0243\end{array}$ & $\begin{array}{c}0,27 \\
0,0319\end{array}$ \\
\hline FormN & $\begin{array}{c}0,27 \\
0,0309\end{array}$ & $\begin{array}{c}0,18 \\
0,1399\end{array}$ & 0,01 & $\begin{array}{c}0,25 \\
0,0465\end{array}$ & $\begin{array}{c}0,35 \\
0,0045\end{array}$ & $\begin{array}{c}0,62 \\
<0,0001\end{array}$ & $\begin{array}{c}0,20 \\
0,1122\end{array}$ & $\begin{array}{c}0,22 \\
0,0764\end{array}$ & $\begin{array}{c}0,36 \\
0,0031\end{array}$ & $\begin{array}{c}0,29 \\
0,0172\end{array}$ & $\begin{aligned} & 0,48 \\
< & 0,0001\end{aligned}$ \\
\hline For & $\begin{array}{c}0,27 \\
0,0307\end{array}$ & $\begin{array}{c}0,23 \\
0,0619\end{array}$ & $\begin{array}{c}0,07 \\
0,5817\end{array}$ & $\begin{array}{c}0,27 \\
0,0281\end{array}$ & $\begin{array}{c}0,33 \\
0,0079\end{array}$ & $\begin{array}{c}0,04 \\
0,7033\end{array}$ & $\begin{array}{c}0,52 \\
<\mathbf{0 , 0 0 0 1}\end{array}$ & $\begin{array}{c}0,06 \\
0,5863\end{array}$ & $\begin{array}{c}0,25 \\
0,0435\end{array}$ & $\begin{array}{c}0,07 \\
0,5749\end{array}$ & $\begin{array}{c}0,11 \\
0,3521\end{array}$ \\
\hline FormP & $\begin{array}{c}0,16 \\
0,1999\end{array}$ & $\begin{array}{c}0,28 \\
0,0237\end{array}$ & $\begin{array}{c}0,24 \\
0,0489\end{array}$ & $\begin{array}{c}0,31 \\
0,0127\end{array}$ & $\begin{array}{c}0,18 \\
0,1416\end{array}$ & $\begin{array}{c}0,23 \\
0,0623\end{array}$ & $\begin{array}{c}0,07 \\
0,5543\end{array}$ & $\begin{array}{c}0,65 \\
<0,0001\end{array}$ & $\begin{array}{c}0,12 \\
0,3202\end{array}$ & $\begin{array}{c}0,23 \\
0,0659\end{array}$ & $\begin{array}{c}0,11 \\
0,3882\end{array}$ \\
\hline FormQ & $\begin{array}{c}0,42 \\
0,0006\end{array}$ & $\begin{array}{c}0,32 \\
0,0095\end{array}$ & $\begin{array}{c}0,30 \\
0,0157\end{array}$ & $\begin{array}{c}0,62 \\
<\mathbf{0 , 0 0 0 1}\end{array}$ & $\begin{array}{c}0,31 \\
0,0129\end{array}$ & $\begin{array}{c}0,40 \\
0,0011\end{array}$ & $\begin{array}{c}0,32 \\
0,0095\end{array}$ & $\begin{array}{c}0,30 \\
0,0157\end{array}$ & $\begin{array}{c}0,62 \\
<\mathbf{0 , 0 0 0 1}\end{array}$ & $\begin{array}{c}0,31 \\
0,0129\end{array}$ & $\begin{array}{c}0,40 \\
0,0011\end{array}$ \\
\hline FormR & $\begin{array}{c}0,05 \\
0,6585\end{array}$ & $\begin{array}{c}0,06 \\
0,6276\end{array}$ & $\begin{array}{c}0,01 \\
0,8855\end{array}$ & $\begin{array}{c}0,36 \\
0,0033\end{array}$ & $\begin{array}{c}0,24 \\
0,0549\end{array}$ & $\begin{array}{c}0,19 \\
0,1319\end{array}$ & $\begin{array}{c}0,15 \\
0,2222\end{array}$ & $\begin{array}{c}0,24 \\
0,0517\end{array}$ & $\begin{array}{c}0,14 \\
0,2583\end{array}$ & $\begin{array}{c}0,50 \\
<\mathbf{0 , 0 0 0 1}\end{array}$ & $\begin{array}{c}0,28 \\
0,0213\end{array}$ \\
\hline FormST & $\begin{array}{c}0,11 \\
0,3936\end{array}$ & $\begin{array}{c}-0,03 \\
0,7637\end{array}$ & $\begin{array}{c}0,11 \\
0,3520\end{array}$ & $\begin{array}{c}0,21 \\
0,0992\end{array}$ & $\begin{array}{c}0,21 \\
0,0843\end{array}$ & $\begin{array}{c}0,38 \\
0,001\end{array}$ & $\begin{array}{c}0,08 \\
0,5032\end{array}$ & $\begin{array}{c}0,19 \\
0,1190\end{array}$ & $\begin{array}{c}0,30 \\
0,0141\end{array}$ & $\begin{array}{c}0,30 \\
0,0160\end{array}$ & $\begin{array}{c}0,59 \\
<\mathbf{0 , 0 0 0 1}\end{array}$ \\
\hline
\end{tabular}

Notas. *Autoeficácia ocupacional para formação de categoria CNAE na atividade A. **Interesses Ocupacionais de categoria CNAE na atividade A. Valores significativos em negrito. 
Os resultados do pré-teste para o GE mostraram correlações positivas e significativas entre autoeficácia ocupacional de formação e de interesses ocupacionais para todas as seções da CNAE. As correlações identificadas foram de intensidades de moderadas a fortes, variando entre 0,60 a 0,74 . Outras correlações positivas e significativas entre seções não correspondentes foram identificadas em 26 ocorrências, com intensidades que variaram entre fracas e moderadas (de 0,38 a 0,56 ) como visto na Tabela 4. Desse modo, os estudantes percebiam-se autoeficazes para completar com sucesso a formação necessária para atuar em determinadas ocupações das seções CNAE e se interessavam por ocupações de outras seções também.

Tabela 4

Correlações de Spearman entre Autoeficácia Ocupacional (formação) e Interesses Ocupacionais pela CNAE - GE (pré-teste) - $(N=103)$

\begin{tabular}{|c|c|c|c|c|c|c|c|c|c|c|c|}
\hline & $\begin{array}{l}\text { Inter } \\
A^{* *}\end{array}$ & $\begin{array}{c}\text { Inter } \\
\text { BCDEF }\end{array}$ & $\begin{array}{l}\text { Inter } \\
\text { GHI }\end{array}$ & $\begin{array}{c}\text { Inter } \\
\text { JK }\end{array}$ & $\begin{array}{c}\text { Inter } \\
\mathrm{M}\end{array}$ & $\begin{array}{c}\text { Inter } \\
\mathrm{N}\end{array}$ & $\begin{array}{c}\text { Inter } \\
\text { OU }\end{array}$ & $\begin{array}{c}\text { Inter } \\
\mathrm{P}\end{array}$ & $\begin{array}{c}\text { Inter } \\
\mathrm{Q}\end{array}$ & $\begin{array}{c}\text { Inter } \\
\mathrm{R}\end{array}$ & $\begin{array}{l}\text { Inter } \\
\text { ST }\end{array}$ \\
\hline FormA & $\begin{array}{c}0,67 \\
<\mathbf{0 , 0 0 0 1}\end{array}$ & $\begin{array}{c}0,53 \\
<0,0001\end{array}$ & $\begin{array}{c}0,45 \\
<0,0001\end{array}$ & $\begin{array}{c}0,22 \\
0,0222\end{array}$ & $\begin{array}{c}0,35 \\
0,0002\end{array}$ & $\begin{array}{c}0,10 \\
0,2985\end{array}$ & $\begin{array}{c}0,21 \\
0,0277\end{array}$ & $\begin{array}{c}0,18 \\
0,0569\end{array}$ & $\begin{array}{c}0,26 \\
0,0075\end{array}$ & $\begin{array}{c}0,01 \\
0,8507\end{array}$ & $\begin{array}{c}0,09 \\
0,3210\end{array}$ \\
\hline $\begin{array}{l}\text { Form } \\
\text { BCDEF }\end{array}$ & $\begin{array}{c}0,37 \\
0,0001\end{array}$ & $\begin{array}{c}0,72 \\
<0,0001\end{array}$ & $\begin{array}{c}\mathbf{0 , 5 0} \\
<\mathbf{0 , 0 0 0 1}\end{array}$ & $\begin{array}{c}0,31 \\
0,0011\end{array}$ & $\begin{array}{c}0,35 \\
0,0003\end{array}$ & $\begin{array}{l}0,20 \\
0,03\end{array}$ & $\begin{array}{c}0,22 \\
0,0207\end{array}$ & 0,3060 & $\begin{array}{c}0,17 \\
0,0835\end{array}$ & $\begin{array}{c}-0,04 \\
0,6269\end{array}$ & $\begin{array}{c}0,01 \\
0,9130\end{array}$ \\
\hline $\begin{array}{l}\text { Form } \\
\text { GHI }\end{array}$ & 0,0002 & $\begin{array}{c}0,56 \\
<0,0001\end{array}$ & $\begin{array}{c}0,68 \\
<0,0001\end{array}$ & $\begin{array}{c}0,27 \\
0,004\end{array}$ & 0,0004 & $\begin{array}{c}0,30 \\
0,0018\end{array}$ & $\begin{array}{c}0,17 \\
0,0690\end{array}$ & 0,0059 & 0,1387 & $\begin{array}{c}0,12 \\
0,2090\end{array}$ & $\begin{array}{c}0,16 \\
0,1062\end{array}$ \\
\hline Forn & $\begin{array}{c}0,22 \\
0,0205\end{array}$ & $\begin{array}{c}0,38 \\
<0,0001\end{array}$ & $\begin{array}{c}0,37 \\
0,001\end{array}$ & $\begin{array}{c}0,69 \\
<, 0001\end{array}$ & $\begin{array}{c}0,41 \\
<0,0001\end{array}$ & $\begin{array}{c}0,40 \\
<\mathbf{0 , 0 0 0 1}\end{array}$ & $\begin{array}{c}0,18 \\
0,0598\end{array}$ & $\begin{array}{c}0,21 \\
0,0309\end{array}$ & $\begin{array}{c}0,25 \\
0,0085\end{array}$ & $\begin{array}{c}0,30 \\
0,0015\end{array}$ & $\begin{array}{c}0,22 \\
0,0245\end{array}$ \\
\hline FormM & $\begin{array}{c}0,36 \\
0,0002\end{array}$ & $\begin{array}{c}0,50 \\
<\mathbf{0 , 0 0 0 1}\end{array}$ & $\begin{array}{c}0,49 \\
<0,0001\end{array}$ & $\begin{array}{c}0,42 \\
<0,0001\end{array}$ & $\begin{array}{c}0,60 \\
<0,0001\end{array}$ & $\begin{array}{c}0,39 \\
<\mathbf{0 , 0 0 0 1}\end{array}$ & $\begin{array}{c}0,37 \\
<\mathbf{0 , 0 0 0 1}\end{array}$ & $\begin{array}{c}0,28 \\
0,0041\end{array}$ & $\begin{array}{c}0,41 \\
<0,0001\end{array}$ & $\begin{array}{c}0,31 \\
0,0013\end{array}$ & $\begin{array}{c}0,23 \\
0,0178\end{array}$ \\
\hline FormN & $\begin{array}{c}0,08 \\
0,3954\end{array}$ & $\begin{array}{c}0,24 \\
0,0125\end{array}$ & $\begin{array}{c}0,29 \\
0,0022\end{array}$ & $\begin{array}{c}0,36 \\
0,0002\end{array}$ & $\begin{array}{c}0,33 \\
0,0005\end{array}$ & $\begin{array}{c}0,74 \\
<0,0001\end{array}$ & $\begin{array}{c}0,12 \\
0,2121\end{array}$ & $\begin{array}{c}0,34 \\
0,0004\end{array}$ & $\begin{array}{c}0,24 \\
0,0120\end{array}$ & $\begin{array}{c}0,19 \\
0,0472\end{array}$ & $\begin{array}{c}0,28 \\
0,0038\end{array}$ \\
\hline FormOU & $\begin{array}{c}0,23 \\
0,0188\end{array}$ & $\begin{array}{c}0,38 \\
<\mathbf{0 , 0 0 0 1}\end{array}$ & $\begin{array}{c}0,34 \\
0,0004\end{array}$ & $\begin{array}{c}0,29 \\
0,0029\end{array}$ & $\begin{array}{c}0,51 \\
<0,0001\end{array}$ & $\begin{array}{c}0,32 \\
0,0009\end{array}$ & $\begin{array}{c}\mathbf{0 , 6 5} \\
<, 0001\end{array}$ & $\begin{array}{c}0,19 \\
0,0441\end{array}$ & $\begin{array}{c}\mathbf{0 , 3 9} \\
<, 0001\end{array}$ & $\begin{array}{c}0,23 \\
0,0150\end{array}$ & $\begin{array}{c}0,13 \\
0,1726\end{array}$ \\
\hline FormP & $\begin{array}{c}0,22 \\
0,0229\end{array}$ & $\begin{array}{c}0,22 \\
0,0196\end{array}$ & $\begin{array}{c}0,37 \\
0,0001\end{array}$ & $\begin{array}{c}0,24 \\
0,0129\end{array}$ & $\begin{array}{c}0,27 \\
0,0047\end{array}$ & $\begin{array}{c}0,40 \\
<0,0001\end{array}$ & $\begin{array}{c}0,23 \\
0,0159\end{array}$ & $\begin{array}{c}0,69 \\
<0,0001\end{array}$ & $\begin{array}{c}0,31 \\
0,0014\end{array}$ & $\begin{array}{c}0,22 \\
0,0197\end{array}$ & $\begin{array}{c}0,24 \\
0,0109\end{array}$ \\
\hline FormQ & $\begin{array}{c}0,32 \\
0,0009\end{array}$ & $\begin{array}{c}0,27 \\
0,0044\end{array}$ & $\begin{array}{c}0,30 \\
0,0020\end{array}$ & $\begin{array}{c}0,21 \\
0,0261\end{array}$ & $\begin{array}{c}0,44 \\
<0,0001\end{array}$ & $\begin{array}{c}0,34 \\
0,0003\end{array}$ & $\begin{array}{c}0,26 \\
0,0069\end{array}$ & $\begin{array}{c}0,39 \\
<0,0001\end{array}$ & $\begin{array}{c}0,64 \\
<0,0001\end{array}$ & $\begin{array}{c}0,21 \\
0,0300\end{array}$ & $\begin{array}{c}0,32 \\
0,0008\end{array}$ \\
\hline FormR & $\begin{array}{c}0,14 \\
0,1548\end{array}$ & $\begin{array}{c}0,14 \\
0,1398\end{array}$ & $\begin{array}{c}0,34 \\
0,0004\end{array}$ & $\begin{array}{c}0,39 \\
<0,0001\end{array}$ & $\begin{array}{c}0,41 \\
<0,0001\end{array}$ & $\begin{array}{c}0,25 \\
0,0087\end{array}$ & $\begin{array}{c}0,25 \\
0,0108\end{array}$ & $\begin{array}{c}0,34 \\
0,0004\end{array}$ & $\begin{array}{c}0,30 \\
0,0018\end{array}$ & $\begin{array}{c}0,60 \\
<\mathbf{0 , 0 0 0 1}\end{array}$ & $\begin{array}{c}0,36 \\
0,0001\end{array}$ \\
\hline FormST & $\begin{array}{c}0,29 \\
0,0028\end{array}$ & $\begin{array}{c}0,13 \\
0,1636\end{array}$ & $\begin{array}{c}\mathbf{0 , 4 0} \\
<\mathbf{0 , 0 0 0 1}\end{array}$ & $\begin{array}{c}0,24 \\
0,0132\end{array}$ & $\begin{array}{c}0,32 \\
0,0007\end{array}$ & $\begin{array}{c}0,38 \\
<0,0001\end{array}$ & $\begin{array}{c}0,11 \\
0,2330\end{array}$ & $\begin{array}{c}0,53 \\
<\mathbf{0 , 0 0 0 1}\end{array}$ & $\begin{array}{c}0,44 \\
<0,0001\end{array}$ & $\begin{array}{c}0,49 \\
<0,0001\end{array}$ & $\begin{array}{c}0,69 \\
<0,0001\end{array}$ \\
\hline
\end{tabular}

Notas. *Autoeficácia ocupacional para formação de categoria CNAE na atividade A. **Interesses Ocupacionais de categoria CNAE na atividade A. Valores significativos em negrito.

Os resultados do GE no pós-teste indicaram correlações positivas e significativas entre as crenças de autoeficácia ocupacional de formação e de interesses ocupacionais para todas as seções da CNAE correspondentes. As intensidades das correlações foram de moderadas a fortes, com predomínio das fortes, variando en- tre 0,60 e 0,77 . As seções não correspondentes também apresentaram correlações positivas e significativas em trinta e quatro ocorrências com intensidades que transitaram de fracas a moderadas, com predomínio das moderadas, variando entre 0,37 e 0,61 , como apresentado na Tabela 5. 
Tabela 5

Correlações de Spearman entre Autoeficácia Ocupacional (formação) e Interesses Ocupacionais pela CNAE - GE (pós-teste) - $(N=103)$

\begin{tabular}{|c|c|c|c|c|c|c|c|c|c|c|c|}
\hline & $\begin{array}{l}\text { Inter } \\
A^{* *}\end{array}$ & $\begin{array}{c}\text { Inter } \\
\text { BCDEF }\end{array}$ & $\begin{array}{l}\text { Inter } \\
\text { GHI }\end{array}$ & $\begin{array}{l}\text { Inter } \\
\text { JK }\end{array}$ & $\begin{array}{c}\text { Inter } \\
\mathrm{M}\end{array}$ & $\begin{array}{c}\text { Inter } \\
\mathrm{N}\end{array}$ & $\begin{array}{c}\text { Inter } \\
\text { OU }\end{array}$ & $\begin{array}{c}\text { Inter } \\
\mathrm{P}\end{array}$ & $\begin{array}{c}\text { Inter } \\
\mathrm{Q}\end{array}$ & $\begin{array}{c}\text { Inter } \\
\mathrm{R}\end{array}$ & $\begin{array}{c}\text { Inter } \\
\text { ST }\end{array}$ \\
\hline Forr & $\begin{array}{c}0,60 \\
<\mathbf{0 , 0 0 0 1}\end{array}$ & $\begin{array}{c}0,39 \\
<\mathbf{0 , 0 0 0 1}\end{array}$ & $\begin{array}{c}0,38 \\
<0,0001\end{array}$ & $\begin{array}{c}0,18 \\
0,0588\end{array}$ & $\begin{array}{c}0,37 \\
<\mathbf{0 , 0 0 0 1}\end{array}$ & $\begin{array}{c}0,21 \\
0,0287\end{array}$ & $\begin{array}{c}0,14 \\
0,1360\end{array}$ & $\begin{array}{c}0,21 \\
0,0308\end{array}$ & $\begin{array}{c}0,33 \\
0,0005\end{array}$ & $\begin{array}{c}0,30 \\
0,0019\end{array}$ & $\begin{array}{c}0,32 \\
0,0007\end{array}$ \\
\hline $\begin{array}{l}\text { Form } \\
\text { BCDEF }\end{array}$ & $\begin{array}{c}0,44 \\
<0,0001\end{array}$ & $\begin{array}{c}0,75 \\
<0,0001\end{array}$ & $\begin{array}{c}\mathbf{0 , 4 7} \\
<\mathbf{0 , 0 0 0 1}\end{array}$ & $\begin{array}{c}0,27 \\
0,0052\end{array}$ & $\begin{array}{c}0,36 \\
0,0002\end{array}$ & $\begin{array}{c}0,22 \\
0,0209\end{array}$ & $\begin{array}{c}0,15 \\
0,1244\end{array}$ & $\begin{array}{r}0,0 \\
0,48\end{array}$ & $\begin{array}{c}0,13 \\
0,1682\end{array}$ & $\begin{array}{c}0,11 \\
0,2496\end{array}$ & $\begin{array}{c}0,11 \\
0,2284\end{array}$ \\
\hline Form & $\begin{array}{c}0,57 \\
<\mathbf{0 , 0 0 0 1}\end{array}$ & $\begin{array}{c}0,52 \\
<0,0001\end{array}$ & $\begin{aligned} & 0,73 \\
< & \mathbf{0 , 0 0 0 1}\end{aligned}$ & $\begin{array}{c}0,32 \\
0,0008\end{array}$ & $\begin{array}{c}0,42 \\
<0,0001\end{array}$ & $\begin{array}{c}0,31 \\
0,0012\end{array}$ & $\begin{array}{c}0,14 \\
0,1508\end{array}$ & $\begin{array}{r}0,3 \\
0,0 \mathrm{C}\end{array}$ & $\begin{array}{c}0,25 \\
0,0091\end{array}$ & $\begin{array}{c}0,30 \\
0,0020\end{array}$ & $\begin{array}{c}0,33 \\
0,0005\end{array}$ \\
\hline Forn & $\begin{array}{c}0,24 \\
0,0111\end{array}$ & $\begin{array}{c}0,33 \\
0,0005\end{array}$ & $\begin{array}{c}0,32 \\
0,0009\end{array}$ & $\begin{array}{c}0,73 \\
<0,0001\end{array}$ & $\begin{array}{c}0,49 \\
<0,0001\end{array}$ & $\begin{array}{c}0,41 \\
<0,0001\end{array}$ & $\begin{array}{c}0,23 \\
0,0161\end{array}$ & $\begin{array}{c}0,08 \\
0,4025\end{array}$ & $\begin{array}{c}0,20 \\
0,0414\end{array}$ & $\begin{array}{c}0,36 \\
0,0001\end{array}$ & $\begin{array}{c}0,24 \\
0,0143\end{array}$ \\
\hline Forl & $\begin{array}{c}0,44 \\
<0,0001\end{array}$ & $\begin{array}{c}0,39 \\
<0,0001\end{array}$ & $\begin{array}{c}0,35 \\
0,0002\end{array}$ & $\begin{array}{c}0,39 \\
<\mathbf{0 , 0 0 0 1}\end{array}$ & $\begin{array}{c}0,61 \\
<0,0001\end{array}$ & $\begin{array}{c}0,34 \\
0,0004\end{array}$ & $\begin{array}{c}0,31 \\
0,0011\end{array}$ & $\begin{array}{c}0,26 \\
0,0060\end{array}$ & $\begin{array}{c}0,45 \\
<0,0001\end{array}$ & $\begin{array}{c}0,46 \\
<0,0001\end{array}$ & $\begin{array}{c}\mathbf{0 , 3 9} \\
<\mathbf{0 , 0 0 0 1}\end{array}$ \\
\hline Forr & $\begin{array}{c}0,25 \\
0,0087\end{array}$ & $\begin{array}{c}0,27 \\
0,0046\end{array}$ & $\begin{array}{c}\mathbf{0 , 3 7} \\
<\mathbf{0 , 0 0 0 1}\end{array}$ & $\begin{array}{c}0,38 \\
<0,0001\end{array}$ & $\begin{array}{c}0,51 \\
<, 0001\end{array}$ & $\begin{array}{c}0,76 \\
<0,0001\end{array}$ & $\begin{array}{c}0,26 \\
0,0072\end{array}$ & $\begin{array}{c}0,36 \\
0,0001\end{array}$ & $\begin{array}{c}0,43 \\
<\mathbf{0 , 0 0 0 1}\end{array}$ & $\begin{array}{c}0,33 \\
0,0005\end{array}$ & $\begin{array}{c}0,46 \\
<0,0001\end{array}$ \\
\hline FormOU & $\begin{array}{c}0,19 \\
0,0508\end{array}$ & $\begin{array}{c}0,23 \\
0,0188\end{array}$ & $\begin{array}{c}0,24 \\
0,0126\end{array}$ & $\begin{array}{c}0,18 \\
0,0582\end{array}$ & $\begin{array}{c}0,45 \\
<0,0001\end{array}$ & $\begin{array}{c}0,31 \\
0,0013\end{array}$ & $\begin{array}{c}0,70 \\
<\mathbf{0 , 0 0 0 1}\end{array}$ & $\begin{array}{c}0,24 \\
0,0123\end{array}$ & $\begin{array}{c}0,32 \\
0,0009\end{array}$ & $\begin{array}{c}0,27 \\
0,0053\end{array}$ & $\begin{array}{c}0,16 \\
0,1030\end{array}$ \\
\hline FormP & $\begin{array}{c}0,23 \\
0,0185\end{array}$ & $\begin{array}{c}0,10 \\
0,2798\end{array}$ & $\begin{array}{c}0,32 \\
0,0008\end{array}$ & $\begin{array}{c}0,03 \\
0,7449\end{array}$ & $\begin{array}{c}0,27 \\
0,0049\end{array}$ & $\begin{array}{c}0,27 \\
0,0050\end{array}$ & $\begin{array}{c}0,18 \\
0,0582\end{array}$ & $\begin{array}{c}0,70 \\
<\mathbf{0 , 0 0 0 1}\end{array}$ & $\begin{array}{c}0,38 \\
<0,00001\end{array}$ & $\begin{array}{c}0,42 \\
<0,0001\end{array}$ & $\begin{array}{c}0,35 \\
0,0002\end{array}$ \\
\hline FormQ & $\begin{array}{c}0,21 \\
0,0279\end{array}$ & $\begin{array}{c}0,04 \\
0,6202\end{array}$ & $\begin{array}{c}0,06 \\
0,4978\end{array}$ & $\begin{array}{c}0,08 \\
0,4072\end{array}$ & $\begin{array}{c}0,40 \\
<0,0001\end{array}$ & $\begin{array}{c}0,25 \\
0,0101\end{array}$ & $\begin{array}{c}0,23 \\
0,0180\end{array}$ & $\begin{array}{c}0,36 \\
0,0001\end{array}$ & $\begin{array}{c}\mathbf{0 , 6 7} \\
<\mathbf{0 , 0 0 0 1}\end{array}$ & $\begin{array}{c}0,45 \\
<, 0001\end{array}$ & $\begin{array}{c}0,45 \\
<0,0001\end{array}$ \\
\hline FormR & $\begin{array}{c}0,34 \\
0,004\end{array}$ & $\begin{array}{c}0,14 \\
0,1488\end{array}$ & $\begin{array}{c}0,28 \\
0,0040\end{array}$ & $\begin{array}{c}0,37 \\
0,0001\end{array}$ & $\begin{array}{c}0,52 \\
<\mathbf{0 , 0 0 0 1}\end{array}$ & $\begin{array}{c}0,22 \\
0,0218\end{array}$ & $\begin{array}{c}0,13 \\
0,1703\end{array}$ & $\begin{array}{c}0,36 \\
0,0002\end{array}$ & $\begin{array}{c}0,42 \\
<0,0001\end{array}$ & $\begin{array}{c}0,74 \\
<, 0001\end{array}$ & $\begin{array}{c}0,50 \\
<\mathbf{0 , 0 0 0 1}\end{array}$ \\
\hline FormST & $\begin{array}{c}0,34 \\
0,0003\end{array}$ & $\begin{array}{c}0,08 \\
0,3925\end{array}$ & $\begin{array}{c}0,34 \\
0,0004\end{array}$ & $\begin{array}{c}0,22 \\
0,0231\end{array}$ & $\begin{array}{c}0,48 \\
<0,0001\end{array}$ & $\begin{array}{c}0,36 \\
0,0002\end{array}$ & $\begin{array}{c}0,11 \\
0,2370\end{array}$ & $\begin{array}{c}\mathbf{0 , 3 7} \\
<\mathbf{0 , 0 0 0 1}\end{array}$ & $\begin{array}{c}\mathbf{0 , 5 1} \\
<\mathbf{0 , 0 0 0 1}\end{array}$ & $\begin{array}{c}0,61 \\
<0,0001\end{array}$ & $\begin{array}{c}\mathbf{0 , 7 7} \\
<\mathbf{0 , 0 0 0 1}\end{array}$ \\
\hline
\end{tabular}

Notas. *Autoeficácia ocupacional para formação de categoria CNAE na atividade A (valendo para sequência da coluna nas diferentes seções). **Interesses Ocupacionais de categoria CNAE na atividade A (valendo para a linha nas diferentes seções). Valores significativos em negrito.

Ao comparar os valores dos coeficientes de correlação entre pré e pós-teste das seções correspondentes da CNAE do GE, é possível identificar uma sutil elevação. Destaca-se que, no pós-teste, a categoria da CNAE M (atividades profissionais, científicas e técnicas) foi a que apresentou maior número de correlações com outras seções, totalizando a quantidade de sete. Observou-se que as intensidades das correlações identificadas nos dados do GC tenderam a diminuir ao se compararem o pré e o pós-teste, ao passo que, para o GE, as intensidades das correlações aumentaram ao longo do tempo.

\section{Discussão}

Os resultados apresentados permitiram verificar correlações positivas e significativas, em ambos os grupos e avaliações (pré e pós-teste), entre as percepções de autoeficácia ocupacional de formação e os interesses ocupacionais dos participantes, não foram identificadas correlações negativas e significativas. O modelo teórico da TSCC de Interesses aponta que a percepção de autoeficácia e a antecipação de resultados no domínio específico tendem a impactar na formação de interesses. Assim, as pessoas desenvol- 
verão suas preferências e gostos por atividades que se percebem eficazes (Brown \& Lent, 2006; Lent et al., 1994). O que foi corroborado com os dados da literatura (Coimbra \& Fontaine, 2010; Lent et al., 1986; Lent et al., 2001; Lent, Brown, Nota et al., 2003; Lent, Brown, Schimidt et al., 2003; Lent, Paixão, Silva, \& Leitão, 2010; Lopez et al., 1997; Nunes \& Noronha, 2009, 2011).

As correlações positivas e significativas encontradas nas seções correspondentes ocorreram no pré-teste e para ambos os grupos pode ser justificada pelo fato de que as pessoas estão expostas a uma série de atividades que realizam, observam outras pessoas realizarem e recebem feedback de outros para as realizarem ou não (Brown \& Lent, 2006). O que pode denotar diferentes fontes de informação de eficácia, sendo para a construção, fortalecimento ou enfraquecimento (experiência de domínio, experiência vicária, persuasão social (Bandura, 1997). Assim elas tenderão a buscar exercer as atividades que considerem possíveis para si e com as quais esperam ter um desempenho satisfatório. Entende-se que o próprio meio no qual o indivíduo está inserido pode contribuir, direta ou indiretamente, em relação à construção de suas crenças de autoeficácia ocupacional. O que sugere que independente da intervenção realizada, os estudantes estão expostos a fontes de informação que podem influenciá-los no desenvolvimento de seus interesses profissionais.

É reconhecido que as próprias experiências dos estudantes na vida escolar e em outros contextos puderam contribuir para as correlações encontradas, partilhando os apontamentos de Kober (2008) a respeito da escola e a carreira. Apesar disso, vale pensar que o desenvolvimento da experiência planejada sobre a carreira aos estudantes pôde, de algum modo, interferir nas percepções de crenças de autoeficácia e em seus interesses (Betz, 2004; Brown \& Lent, 2006; Lent, Hackett, \& Brown, 2004). Visto que as correlações identificadas ocorreram também antes da intervenção, vale pensar sobre quais fontes de informações estavam/estão expostos os estudantes? Pois, na visão da TSCC, as percepções de crenças de autoeficácia contribuem para a evitação ou aproximação do comportamento em questão, e se a pessoa evita algo, ela não se dispõe a aprender ou dominá-lo (Bandura, 1997; Betz, 2004).

De modo geral, as correlações do GC no pós-teste tenderam a se restringir apenas às seções correspondentes. Além disso, apresentaram-se intensidades de correlações menores que o apresentado pelo GE. Enquanto que os dados do pós-teste do GE tenderam a se ampliar, sem se restringir apenas às correlações das mesmas ocupações, dado já observado no pré-teste. $\mathrm{O}$ que sugere que os estudantes do GE percebiam-se autoeficazes para concluir com sucesso a formação para atuar nas ocupações correspondentes e não correspondentes. Vale ressaltar que tal ocorrência no GE foi potencializada após a intervenção, indicativo de uma diversidade maior de aspirações acadêmicas e profissionais desses estudantes, corroborando com os dados da literatura, segundo a qual se aponta que estudantes que se percebiam mais autoeficazes também percebiam maior amplitude nas opções de carreira (Lent et al., 1984, 1986, 1987).

É importante destacar que a intervenção proposta, à qual o GE foi submetido, teve parte de seu conteúdo relacionado à autorregulação da aprendizagem, à definição de objetivos acadêmicos e profissionais, à busca de informações sobre diferentes modalidades de curso superior, além de cursos técnicos e reflexões sobre aspectos da escolha (Azzi et al., 2013). É possível que a experiência de reflexão em sala de aula sobre tais temáticas tenha repercutido de algum modo nesse grupo e favorecido suas percepções. E apesar de Brown e Lent (2006) afirmarem que os interesses tendem a se manterem estáveis, é possível identificar mudanças nos resultados aqui relatados.

Observou-se pelos dados do GE que a seção da CNAE M (atividades profissionais, científicas e técnicas) foi a que apresentou maior número de correlações positivas e significativas (Tabelas 3 e 4). Vale lembrar que para a maioria das ocupações que a compunham é imprescindível à formação pelo ensino superior, o que pode ter tido um papel de filtro, como observado por Coimbra (2000), como correspondeu com a expectativa de aproximadamente $65 \%$ dos estu- 
dantes que indicaram a pretensão de cursar esse nível de ensino (no pós-teste).

A tendência observada nas correlações quanto às seções das ocupações indicaram que houve modificações em relação aos grupos e em relação ao tempo, o que é esperado na literatura ao considerar que as percepções de crenças de autoeficácia que não são fixas (Bandura, 1997). De todo modo ainda vale cuidados, pois as fontes de informação também podem funcionar inversamente, ou seja, podem enfraquecer as percepções de eficácia indicando de algum modo que os sujeitos não sejam capazes de realizar algo, impactando nos interesses, objetivos e ações para tal ocupação (Bandura, 1997; Lent et al., 1994). Destaca-se que as percepções dos estudantes podem ter sido influenciadas pelas possibilidades das ocupações em atividades econômicas próximas e ou distantes para o contexto em que vivem.

Ao terem ampliado as percepções do GE, espera-se que a escolha deles seja qualificada considerando a exploração das ocupações, ainda que estes estudantes estavam na $2^{\mathrm{a}}$ série do ensino médio e que uma efetiva escolha possivelmente ocorresse pelo menos após um ano. Vale lembrar que nem todas as ocupações possíveis de serem exercidas no Brasil foram contempladas na escala, visto que isso parece uma tarefa quase impossível, e talvez desnecessária para o propósito desta pesquisa. Considerando que as crenças de autoeficácia assumem o papel de preditora motivacional (Bandura, 1997) e que os interesses, por sua vez, conduzem para as intenções/objetivos nas atividades e seleção de tarefas (Brown \& Lent, 2006; Lent et al., 1994), ao observar a diminuição das intensidades das correlações encontradas nesta investigação, aponta-se alguma preocupação e a necessidade de novas investigações que busquem identificar as possíveis razões desse achado, em especial do GC. Vale então questionar o conhecimento com que os estudantes se debruçaram para direcionar suas aspirações quanto à diversidade de ocupações de atuação e de possibilidades de realizarem sua formação. Será que tendem a considerar uma posição determinista quanto às ocupações? Sugere-se que para intervenções futuras seja realizada uma formação específica para os facilitadores que a conduzirão, além de incluir os demais construtos da TSCC nas investigações e que possam ser de caráter longitudinal como possibilidade de acompanhamento dos estudantes.

\section{Referências}

Aguiar, F. H. R., \& Conceição, M. I. G. (2011). Orientação vocacional como tema transversal: Uma experiência com profissionais da educação. Revista Brasileira de Orientação Profissional, 12(1), 107-117.

Aita, E. B., Ricci, P. S. P., \& Tuleski, S. C. (2012). A orientação profissional na perspectiva da psicologia histórico-cultural. Relato de experiência. Revista Semestral da Associação Brasileira de Psicologia Escolar e Educacional, 16(1), 175-177. doi: http://dx.doi.org/10.1590/S141385572012000100019

Azzi, R. G., Dantas, M. A., Benassi, M. T., \& Guerreiro-Casanova, D. C. (2013). O futuro está logo ali, Elpídio - Entre nesta conversa sobre pensar o que vem adiante. São Paulo, SP: Casa do Psicólogo.

Bandura, A. (1986). Social Foundations of thought and action. A Social Cognitive Theory. Englewood Cliffs, NJ: Prentice-Hall.

Bandura, A. (1997). Self-efficacy: The exercise of control. New York: W. H. Freeman.

Bandura, A. (2006). Adolescent development from an agentic perspective. In F. Pajares \& T. Urdan, Self-efficacy beliefs of adolescents (pp. 1-43). Greenwich, CT Information Age.

Bandura, A. (2008). O sistema do self no determinismo recíproco. In A. Bandura, R. G. Azzi, \& S. Polydoro, Teoria Social Cognitiva: Conceitos Básicos (pp. 176-187). Porto Alegre, RS: Artmed.

Betz, N. E. (2004). Contributions of self-efficacy Theory to career counseling: A personal perspective. The Career Development Quarterly, 52, 340-353. doi: https://doi. org/10.1002/j.2161-0045.2004.tb00950.x

Betz, N. E., \& Hackett, G. (1981). The relationship of career-related self-efficacy expectations to perceived career options in college women and men. Journal of Counseling Psychology, 28(5), $399-410$. 
Betz, N. E., \& Shifano, R. S. (2000). Evaluation of an Intervention to Increase Realistic self-efficacy and interests in College Women. Journal of Vocational Behavior, 56, 35-52. doi: https://doi. org/10.1006/jvbe.1999.1690

Brown, S. D., \& Lent, R. W. (2006). Preparing adolescents to make career decisions. In F. Pajares \& T. Urdan (Eds.), Self-efficacy beliefs of adolescents (pp. 201-223). Greenwich, CT: Information Age.

Campos, L. F. L. (2004). Métodos e Técnicas de Pesquisa em Psicologia. São Paulo, SP: Alínea.

Coimbra, S. M. G. (2000). Estudo diferencial da autoeficácia em alunos do $9^{\circ}$ ano de escolaridade (Dissertação de mestrado, Universidade do Porto, Faculdade de Psicologia e de Ciências da Educação, Portugal).

Coimbra, S. M., \& Fontaine, A. M. (2010). Será que sou capaz? Estudo diferencial de autoeficácia com alunos do nono ano. Revista Brasileira de Orientação Profissional, 11(1), 5-22.

Dancey, C. P., \& Reidy, J. (2006). Estatística sem matemática para a psicologia: Usando SPSS para Psicólogos. Porto Alegre, RS: Artmed.

Dantas, M. A. (2015). Autoeficácia ocupacional e de decisão de carreira: Análise de uma intervenção em estudantes do ensino médio público (Tese de doutorado, Faculdade de Educação, Universidade Estadual de Campinas, SP, Brasil).

Dantas, M. A., \& Azzi, R. G. (2015). Autoeficácia ocupacional e interesses percebidos por estudantes do Ensino Médio público. Revista Psicologia: Ensino \& Formação, 6, 52-71.

Dantas, M. A., Azzi, R. G., \& Noronha, A. P. P. (s.d.). Evidências de validade da Escala de Autoeficácia Ocupacional de Formação e Interesses. Manuscrito não publicado.

Guerreiro-Casanova, D. C., Azzi, R. G., \& Dantas, M. A. (2010). Autoeficácia acadêmica: Possibilidade para refletir sobre o ensino médio. EccoS - Revista Cientifica, 12(10), 51-68.

Instituto Brasileiro de Geografia e Estatística. (2007). Classificação Nacional das Atividades Econômicas (Versão 2.0). Rio de Janeiro, RJ: Autor.

Kober, C. M. (2008). Tempo de decidir: Produção da escolha profissional entre jovens do ensino médio (Tese de doutorado, Faculdade de Educação, Universidade de Campinas, SP, Brasil).
Lamas, K. C. A., Pereira, S. M., \& Barbosa, A. J. G. (2008). Orientação Profissional na escola: Uma pesquisa com intervenção. Psicologia em Pesquisa UFJF, 2(1), 60-68.

Lent, R. W., \& Brown, S. D. (2006). On conceptualizing and assessing Social cognitive constructs in career research: A measurement guide. Journal of Career Assessment, 1, 12-35.

Lent, R. W., Brown, S. D., \& Hackett, G. (1994). Toward a unifying Social Cognitive Theory of career and academic interest, choice, and performance. Journal of Vocational Behaviors, 45, 79-122. doi: https://doi.org/10.1006/ jvbe.1994.1027

Lent, R. W., Brown, S. D., \& Larkin, K. C. (1984). Relation of self-efficacy expectations to Academic Achievement and Persistence. Journal of Counseling Psychology, 31(3), 356-362.

Lent, R. W., Brown, S. D., \& Larkin, K. C. (1986). Self-efficacy in the Academic Performance and Perceived Career Options. Journal of Counseling Psychology, 33(3), 265-269.

Lent, R. W., Brown, S. D., \& Larkin, K. C. (1987). Comparison of Three Theoretically derived variables in predicting Career and Acadmeic Behavior: Self-efficacy, interest congruence, and consequence thinking. Journal of Counseling Psychology, 34(3), 293-298. doi: 10.1037/00220167.34.3.293

Lent, R. W., Brown, S. D., Brenner, B., Chopra, S. B., Davis, T., Talleyrand, R., \& Suthakaran, V. (2001). The role of contextual supports and barriers in the choice of math/science educational options: A Test of Social Cognitive Hypotheses. Journal of Counseling Psychology, 48(4), 474-483. doi: http://dx.doi.org/10.1037/00220167.48.4.474

Lent, R. W., Brown, S. D., Nota, L., \& Soresi, S. (2003). Testing social cognitive interest and choice hypotheses across Holland types in Italian high school students. Journal of Vocational Behavior, 62, 101-118. doi: https://doi. org/10.1016/S0001-8791(02)00057-X

Lent, R. W., Brown, S. D., Schimidt, J., Brenner, H. L., Lions, H., \& Treistman, D. (2003). Relation of contextual supports and barriers to choice behavior in engineering majors: Test of alternative Social Cognitive Models. Journal of Counseling Psychology, 50(4), 458-465. doi: http://dx.doi. org/10.1037/0022-0167.50.4.458 
Lent, R. W., Hackett, G., \& Brown, S. D. (2004). Una perpsectiva social cognitive de la transición entre la escuela y el trabajo. Evaluar, 4.

Lent, R. W., Paixão, M. P., Silva, J. T., \& Leitão, L. M. (2010). Predicting occupational interest and choice aspirations in Portuguese high school students: A test of social cognitive career theory. Journal of Vocational Behavior, 76, 244-251. doi: 10.1016/j.jvb.2009.10.001

Lopez, F. G., Lent, R. W., Brown, S. D., \& Gore, P. A. J. (1997). Role of Social-Cognitive Expectations in High Shool studants' MathematicsRelated Interest and Performance. Journal of Counseling Psychology, 44(1), 44-52.

Martín, M. A. C., \& Tejedor, E. M. (2004). Autoeficácia y Madurez Vocacional. Psicothema (Espanha), 16(2), 229-234.

Melo-Silva, L. L., Bonfim, T. A., Esbrogeo, M. C., \& Soares, D. H. P. (2003). Um estudo preliminar sobre práticas em Orientação Profissional. Revista Brasileira de Orientação Profissional, 4(1-2), 21-34

Ministério da Educação. (2000). Parâmetros curriculares nacionais do ensino médio. Brasília, DF: Autor.

Nunes, M. F. O., \& Noronha, A. P. P. (2009). Autoeficácia para atividades ocupacionais e interesses profssionais em estudantes do Ensino Médio. Psicologia: Ciência e Profissão, 29(1), 102-115. doi: http://dx.doi.org/10.1590/S141498932009000100009
Nunes, M. F. O., \& Noronha, A. P. P. (2011). Associações entre autoeficácia para atividades ocupacionais e interesses em adolescentes. Psicologia: Reflexão e Crítica, 24(1), 1-9.

Polydoro, S. A. J., Vieira, D., Azzi, R. G., \& Dantas, M. A. (2012). Avaliação da autoeficácia no domínio de carreira. In E. Boruchovitch, A. A. A. Santos, \& E. Nascimento (Eds.), Avaliação Psicológica nos contextos educativo e psicossocial (pp. 301-328). São Paulo, SP: Casa do Psicólogo.

Teixeira, M. O. (2007). As crenças de eficácia acadêmica na formação dos interesses e das escolhas vocacionais. Psychologica, 44, 11-23.

Valore, L. A., \& Cavallet, L. H. R. (2012). Escolha e orientação profissional de estudantes de curso pré-vestibular popular. Psicologia \& Sociedade, 24(2), 354-363.

Wang, J., Zhang, D., \& Shao, J. (2010). Group training on the improvement of college studants'career decision-making self-efficacy. Health, 2(6), 551-556. doi: 10.4236/health.2010.26082

Recebido: 20/06/2016

$1^{a}$ revisão: 02/05/2017

Aceite final: 02/05/2017

(cc)BY (C) O(s) autor(es), 2018. Acesso aberto. Este artigo está distribuído nos termos da Licença Internacional Creative Commons Atribuição 4.0 (http://creativecommons.org/licenses/by/4.0/), que permite o uso, distribuição e reprodução sem restrições em qualquer meio, desde que você dê crédito apropriado ao(s) autor(es) original(ais) e à fonte, fornecer um link para a licença Creative Commons e indicar se as alterações foram feitas. 